\title{
Accurate detection of triple vessel disease in patients with exercise induced ST segment depression after infarction
}

\author{
D MANNERING, E D BENNETT, D E WARD, K DAWKINS, M DANCY, \\ H VALANTINE, N MEHTA \\ From the Departments of Medicine One and Cardiology, St George's Hospital and Medical School, London
}

SUMMARY The severity of coronary artery disease is an important determinant of prognosis after acute myocardial infarction. The ability of a symptom limited exercise test to predict the presence of triple vessel disease was assessed in 221 patients three weeks after infarction. Coronary angiography was performed in patients with exercise induced ST segment depression. The presence of ST segment depression alone was poorly indicative of triple vessel disease; however, some specific features of ST segment changes on exercise were of predictive value. Downsloping ST segment configuration alone or horizontal ST segihent depression associated with an early onset and a late recovery time after exercise correctly identified $30(90 \%)$ of 33 patients with triple vessel disease whereas it incorrectly identified only $6(15 \%)$ of 39 patients with single and double vessel disease. An abnormal blood pressure response was also predictive.

In patients with ST segment depression after infarction triple vessel disease can be detected accurately by a combination of the electrocardiographic and haemodynamic variables attained on exercise.

Exercise testing in patients early after myocardial infarction is a valuable diagnostic and prognostic technique. One year mortality in patients with exercise induced ST segment depression has been shown to be $25 \%$ compared with $2 \%$ in patients with no ST segment depression. ${ }^{1}$ Even though the one year mortality rate is significantly higher in patients with ST segment depression on exercise, most of these patients are not at high risk of further cardiac events. There is thus a need to identify more accurately the "at risk" group of patients who may benefit from invasive diagnostic and therapeutic techniques. Furthermore, it has been suggested that reduced exercise tolerance or a poor haemodynamic response on exercise may be more predictive of later complications than ST segment changes. ${ }^{2}$

The purpose of this study was to quantify specific ST segment changes on exercise together with the haemodynamic responses on exercise in a group of

Requests for reprints to Mr D Mannering, Department of Medicine 1, St George's Hospital Medical School, Cranmer Terrace, London SW17 ORE.

Accepted for publication 8 October 1986 patients three weeks after a myocardial infarction and to relate these findings to their subsequent coronary anatomy.

\section{Patients and methods}

\section{PATIENTS}

The study group consisted of 221 consecutive patients under the age of 70 years in whom the diagnosis of a myocardial infarction was based on the presence of at least two of the following three criteria: (a) a typical history of chest pain persisting for at least 30 minutes, $(b)$ new $Q$ waves or evolution of ST-T wave changes, $(c)$ a rise in the cardiac enzyme concentrations of aspartate transaminase, hydroxybutyrate dehydrogenase, or creatine kinase to at least twice the upper limit of normal. The average (SE) age was $57(4) ; 40(18 \%)$ were female. Ninety three $(42 \cdot 2 \%)$ had had an anterior infarction, $94(42 \cdot 6 \%)$ an inferior infarction, $20(8.9 \%)$ a lateral infarction, $4(2.0 \%)$ a true posterior infarction, and $10(4.4 \%)$ had no infarction site indicated by the electrocardiogram. Four showed left bundle branch block and four right bundle branch block on the resting 


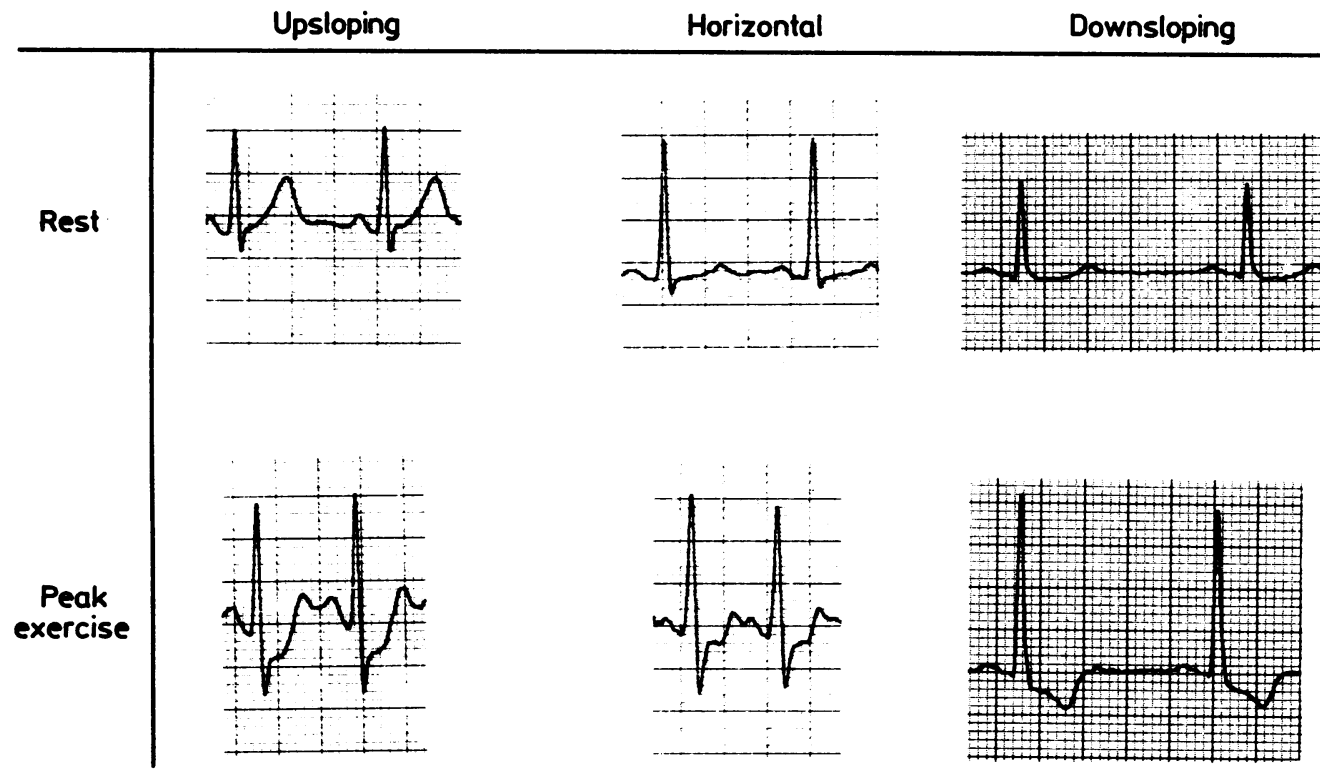

Figure Characterisation of ST segment configuration at peak exercise.

electrocardiogram. One hundred and twenty three patients were taking $\beta$ blockers at the time of exercise. Patients with valvar heart disease or aortic stenosis were excluded from the study.

\section{EXERCISE TESTING}

Symptom limited exercise testing was carried out on a motor driven treadmill by the Bruce protocol. ${ }^{3}$ Patients exercised for $3 \mathrm{~min}$ stages at progressively increasing work loads. A 12 lead electrocardiogram was recorded before exercise with the patient supine and upright, at the end of each 3 minute stage of exercise, immediately after exercise, and every minute during recovery. In addition, leads II, V2, and V5 were continuously monitored throughout exercise. Blood pressure was measured on the right arm by the standard cuff method at the same time as the electrocardiogram was recorded.

Exercise was continued until one of the following end points: (a) $>3 \mathrm{~mm}$ ST segment depression $80 \mathrm{~ms}$ after the $\mathrm{J}$ point in any lead; $(b)$ a fall in systolic blood pressure; (c) occurrence of chest pain, dyspnoea, fatigue, or dizziness; (d) leg cramps. A test was defined as positive if $\geqslant 1 \mathrm{~mm}$ ST segment depression was recorded in any lead. ST segment depression was categorised as slowly unsloping, horizontal, and downsloping configurations (figure). Total exercise time and time to onset of significant ST segment depression on exercise were recorded together with the recovery time from ST segment depression after exercise. The increase in systolic blood pressure at peak exercise was expressed as the percentage increase from the resting value (systolic blood pressure increase). Patients in whom systolie blood pressure did not increase by $>10 \%$ of the resting value at peak exercise were considered to have a poor exercise blood pressure response. The heart rate at the onset of significant ST depression? was expressed as a percentage increase from the reste ing value (heart rate at onset).

\section{CORONARY ANGIOGRAPHY}

Coronary arteriography was performed at 2-4 week after the exercise test on patients with significant ST: segment depression who agreed to undergo the procedure. Twelve patients with no ST segmen? depression underwent this procedure for clinica reasons. The arteriograms were viewed by a radiolo gist who was unaware of the exercise test findings? Significant coronary artery disease was defined as $>70 \%$ proximal luminal narrowing in either the leff. anterior descending, circumflex, or right coronary arteries or the left main stem. Patients were then classified as having single, double, or triple vesset disease.

FOLLOW UP

Patients with a diagnosis of significant triple vesse or left main disease were referred for coronary artery bypass surgery together with those patients in whom symptoms persisted despite optimal medica treatment and in whom the coronary anatomy was suitable for surgery. All other patients were managed medically. 
STATISTICAL ANALYSIS

Unpaired student $t$ tests were applied where appropriate to test for significant differences in the measured exercise variables between the negative and positive test groups and between the patient groups with single, double, and triple vessel disease. We used discriminant analysis (Statistical Package for the Social Sciences) to distinguish statistically between patients with $(a)$ single and double vessel disease and $(b)$ triple vessel disease, using the exercise variables described above as discriminant variables. The optimal discriminatory points were used to determine the sensitivity and specificity of these exercise variables.

\section{Results}

Significant ST segment depression (positive test) was recorded in $89(40 \%)$ patients, 72 of whom underwent coronary angiography. The remaining 17 patients with a positive test either refused to undergo this procedure or had more serious underlying medical conditions. Of the patients who underwent angiography, 24 were diagnosed as having single vessel disease, 15 double vessel disease, and 33 triple vessel disease. Of the 132 patients with no ST segment depression (negative test), 12 underwent coronary angiography for clinical reasons: three were $<35$ years of age, four had significant chest pain, one had a suspected left ventricular aneurysm, one had early exercise induced left bundle branch block, and three became hypotensive on exercise. Single vessel disease was diagnosed in nine, double vessel disease in three; none had triple vessel disease.

There was no significant difference in the resting heart rate between patients with a negative test and those with a positive test ( 77 beats/minute for both groups) or between the rates attained at peak exercise (127 beats/minute for both groups). Exercise time was significantly longer in patients with a negative test $(6.7(0.3)$ minutes) than in the positive test group (5.7 (0.3) minutes) (p < 0.01). The mean (SE) systolic blood pressure increase in the negative test group was $26(3) \%$ compared with $16(2) \%$ in the positive test group ( $p<0.001$ ).

Table 1 shows the mean onset time, recovery time, and ST segment configuration together with the systolic blood pressure increase, heart rate increase at ST depression, and the exercise time for the single, double, and triple vessel disease groups together with the respective $p$ values. Table 2 shows the sensitivity and specificity attained for each exercise variable in distinguishing the two groups: $(a)$ single and double vessel disease and $(b)$ triple vessel disease.

Discriminant analysis demonstrated that downsloping ST segment configuration was the most accurate single exercise variable in predicting severity of disease; it correctly classified $77.8 \%$ of patients. This was followed by ST segment recovery time $(76.4 \%)$; the onset time to significant ST segment depression $(75.0 \%$ ); the increase in heart rate at onset of ST depression ( $72.2 \%)$, and the blood pressure response to exercise $(70 \cdot 8 \%)$. By combining all these exercise variables $90.3 \%$ of patients were correctly classified $(p<0.01)$.

None of the 12 patients with upsloping ST seg-

- Table 2 Sensitivity and specificity of the exercise variables used to distinguish between single and double vessel disease and triple vessel disease

\begin{tabular}{lll}
\hline Exercise variable & $\begin{array}{l}\text { Sensitivity } \\
(\%)\end{array}$ & $\begin{array}{l}\text { Specificity } \\
(\%)\end{array}$ \\
\hline $\begin{array}{l}\text { Downsloping ST depression } \\
\text { Recovery time from ST } \\
\text { depression ( } \geqslant 6 \text { min) }\end{array}$ & 94.9 & 57.6 \\
$\begin{array}{l}\text { Onset time to ST depression } \\
\quad(\leqslant 3 \text { min) }\end{array}$ & $82 \cdot 1$ & 69.7 \\
$\begin{array}{l}\text { Increase in heart rate at ST } \\
\text { depression (<40\%) }\end{array}$ & $66 \cdot 7$ & 84.8 \\
$\begin{array}{l}\text { Increase in systolic blood } \\
\text { pressure ( } \leqslant 10 \%)\end{array}$ & $59 \cdot 0$ & 87.9 \\
\begin{tabular}{l} 
Exercise time (min) \\
\hline
\end{tabular} & $69 \cdot 2$ & 72.7 \\
\hline
\end{tabular}

able 1 Mean (SE) values of all exercise variables in relation to the severity of coronary disease

\begin{tabular}{|c|c|c|c|c|c|c|}
\hline \multirow[b]{2}{*}{ :ercise variable } & \multicolumn{3}{|c|}{ Severity of disease } & \multicolumn{3}{|l|}{$p$ values } \\
\hline & Single & Double & Triple & Single vs double & Single vs triple & Double vs triple \\
\hline \multirow{3}{*}{$\begin{array}{l}\text { zart rate (rest) (beats/min) } \\
\text { zart rate (peak) (beats/min) } \\
\text { iset time to ST depression (min) } \\
\text { :covery time from ST depression (min) } \\
\text { [ segment configuration (No): } \\
\text { Upsloping } \\
\text { Horizontal } \\
\text { Downsloping } \\
\text { 'stolic blood pressure increase (\%) } \\
\text { crease in heart rate at onset of ST } \\
\text { depression (\%) } \\
\text { cercise time (min) }\end{array}$} & $\begin{array}{c}75(3) \\
128(4) \\
5.5(0.4) \\
3.9(0.5)\end{array}$ & $\begin{array}{c}76(4) \\
127(6) \\
2.9(0.4) \\
5.3(0.7)\end{array}$ & $\begin{array}{c}80(3) \\
124(4) \\
2 \cdot 0(0 \cdot 2) \\
8 \cdot 3(0 \cdot 5)\end{array}$ & $\begin{array}{l}\text { NS } \\
\text { NS } \\
<0.001 \\
\text { NS }\end{array}$ & $\begin{array}{l}\text { NS } \\
\text { NS } \\
<0.001 \\
<0.001\end{array}$ & $\begin{array}{l}\text { NS } \\
\text { NS } \\
<0.05 \\
<0.001\end{array}$ \\
\hline & $\begin{array}{l}11 \\
13 \\
0 \\
24 \cdot 4(3 \cdot 2)\end{array}$ & $\begin{array}{l}1 \\
12 \\
2 \\
15 \cdot 8(4 \cdot 7)\end{array}$ & $\begin{array}{l}0 \\
14 \\
19 \\
5 \cdot 1(2 \cdot 7)\end{array}$ & NS & $\begin{array}{l}\chi^{2} \mathrm{p}<0.001 \\
<0.001\end{array}$ & $<0.05$ \\
\hline & $\begin{array}{r}63.4(5.4) \\
6.9(0.5)\end{array}$ & $\begin{array}{r}50.3(8.8) \\
5.8(0.6)\end{array}$ & $\begin{array}{r}29.7(3.4) \\
4.9(0.4)\end{array}$ & $\begin{array}{l}\text { NS } \\
\text { NS }\end{array}$ & $\begin{array}{l}<0.01 \\
<0.01\end{array}$ & $\begin{array}{l}<0.001 \\
\text { NS }\end{array}$ \\
\hline
\end{tabular}


Table 3 Association of early onset time to ST segment depression and late recovery time with severity of disease in patients $\stackrel{.}{.}$ with horizontal ST segment depression

\begin{tabular}{|c|c|c|c|c|}
\hline Severity of disease & $\begin{array}{l}\text { Group } 1 \\
\text { Onset time }>3 \mathrm{~min} \\
\text { Recovery time }<6 \mathrm{~min}\end{array}$ & $\begin{array}{l}\text { Group } 2 \\
\text { Onset time } \leqslant 3 \text { min } \\
\text { Recovery time }<6 \text { min }\end{array}$ & $\begin{array}{l}\text { Group } 3 \\
\text { Onset time > } 3 \text { min } \\
\text { Recovery time } \geqslant 6 \text { min }\end{array}$ & $\begin{array}{l}\text { Group } 4 \\
\text { Onset time } \leqslant 3 \text { min } \\
\text { Recovery time } \geqslant 6 \text { min }\end{array}$ \\
\hline $\begin{array}{l}\text { Single/double vessel } \\
\text { Triple vessel }\end{array}$ & $\begin{array}{r}10 \\
1\end{array}$ & $\begin{array}{l}8 \\
1\end{array}$ & $\begin{array}{l}3 \\
1\end{array}$ & $\begin{array}{r}4 \\
11\end{array}$ \\
\hline
\end{tabular}

ment depression had triple vessel disease whereas 19 of the 21 with downsloping ST segment depression had triple vessel disease. Of the 39 patients with horizontal ST segment depression, however, 14 had triple vessel disease. To separate further this group of patients with horizontal ST segment depression, we used the second and third most powerful discriminant variables (an onset time to significant ST segment depression of $\leqslant 3$ minutes and a recovery time after exercise of $\geqslant 6$ minutes) in association with horizontal ST segment configuration. Four groups of patients with horizontal ST segment depression were then defined:

Group 1-Patients with an onset time of $>3$ minutes and a recovery time of $<6$ minutes.

Group 2-Patients with an onset time of $\leqslant 3$ minutes and a recovery time of $<6$ minutes.

Group 3-Patients with an onset time of $>3$ minutes and a recovery time of $\geqslant 6$ minutes.

Group 4-Patients with onset time of $\leqslant 3$ minutes and a recovery time of $\geqslant 6$ minutes. Table 3 shows these results.

Seventy nine per cent of the 14 patients with triple vessel disease and horizontal ST segment depression were in group 4 whereas only $16 \%$ of those with single or double vessel disease with horizontal ST segment depression were in group 4.

\section{$\beta$ BLOCKERS}

Fifty four (44\%) of the 123 patients taking $\beta$ blockers had significant ST segment depression on exercise compared with $39(39 \%)$ of the 99 patients not taking $\beta$ blockers. There was no significant difference in the systolic blood pressure increase on exercise between patients taking $\beta$ blockers $(23(1 \cdot 7) \%)$ and those who were not $(19 \cdot 8(2 \cdot 0) \%)$. There were significant differences in the resting and peak heart rates and the total exercise time between the two groups (table 4).

Table 4 Mean values ( $S E$ ) for resting and peak heart rates and exercise time in patients taking $\beta$ blockers and in those who were not

\begin{tabular}{lccc}
\hline & B blockers & No B blockers & p value \\
\hline Resting heart rate (beats/min) & $68(2)$ & $90(2)$ & $<0.001$ \\
Peak heart rate (beats/min) & $116(2)$ & $140(2)$ & $<0.001$ \\
Exercise time (min) & $6.9(0.3)$ & $5.8(0.3)$ & $<0.01$ \\
\hline
\end{tabular}

\section{Discussion}

We have shown that the presence of exercise induced ST segment depression alone is a poor pre dictor of severe coronary disease because only $45 \%$ of 74 patients with significant ST segment depresio sion had triple vessel disease shown by angiography $\dot{\dot{\omega}}$ This accords with a recent study ${ }^{4}$ but not with eares lier ones. ${ }^{56}$ We have demonstrated, however, that further analysis of the ST segment variables can predict more accurately the severity of coronar: artery disease.

The absence of downsloping ST segment depres@ sion on exercise was the most specific indicator of the absence of triple vessel disease. Of the group with downsloping ST segment depression none had single vessel disease, $\mathbf{9 . 5} \%$ had double vessel disછ ease, and $90.5 \%$ had triple vessel disease. Fourteer of the 33 patients with triple vessel disease, however? did not have downsloping ST segment depressionfo Given the widespread distribution of horizontal $S \frac{D}{D}$ segment depression in patients with single and double vessel disease and triple vessel disease? further analysis of this configuration would bo necessary to determine which ST segment charace teristics are of diagnostic value. When exercise induced ST segment depression occurs in patient with triple vessel disease significant ST changes are likely to appear within the first stage of exercise which was significantly earlier than for single ox double vessel disease. Moreover, patients in whong the ischaemic ST segment persists for $>6$ minute after exercise are likely to have triple vessel disease? Subdivision of patients with horizontal ST segmen depression into those with early onset and late. recovery times allows triple vessel disease to be diago nosed with greater accuracy. Eleven $(79 \%)$ of the 1 it patients with triple vessel disease and horizontal $S \mathrm{E}$ segment depression had early onset and late recovo ery times compared with only four $(16 \%)$ of the 25 with single or double vessel disease with horizontal ST segment depression. When these 14 patients were added to those patients in whom a downsloping configuration was a marker for triple vessel disease $30(90 \%)$ of the 33 patients with triple vessel diseas and ST segment depression were correctly identified with only $6(15 \%)$ of the 39 patients with single and double vessel disease being misclassified. 
Specific ST segment analysis can identify triple vessel disease more accurately than the simple presence of ST segment depression, which can only be regarded as a marker for the presence of myocardial ischaemia not its severity.

Recent studies have shown a significant association between a poor systolic blood pressure response on exercise and subsequent cardiac mortality in patients after myocardial infarction. ${ }^{278}$ This abnormal exercise response has been attributed to poor left ventricular function caused by a larger infarct. ${ }^{9}$ The results of our study suggest that a poor blood pressure response on exercise is associated with triple vessel disease. This group of patients had a significantly lower blood pressure increase than patients with single or double vessel disease. This observation accords with previous studies. ${ }^{410}$ Sullivan et al reported a significant association between a poor blood pressure response on exercise and multivessel disease. ${ }^{4}$ Further, they observed no significant difference in the resting ejection fraction between those patients with a good blood pressure response and those with an inadequate blood pressure response, suggesting that this inadequate response was not a product of poor left ventricular function. These results suggest that a poor blood pressure response may be a function of increased myocardial ischaemia.

No significant differences were seen in the peak heart rate attained on exercise by patients with single, double, and triple vessel disease. In patients with triple vessel disease, however, the increase in heart rate at the onset of significant ST segment depression was lower than in patients with single and double vessel disease. This suggests that patients with severe coronary artery disease increase their heart rate, and thus myocardial oxygen consumption, to a lesser extent before the onset of myocardial ischaemia.

A low maximum heart rate has been shown to be significantly associated with multivessel disease in patients with stable angina. ${ }^{11}$ This association is not so clearly demonstrated in patients after myocardial infarction, mainly because there is left ventricular dysfunction. In contrast, Jennings et al reported a significant association between a high heart rate at peak exercise and subsequent cardiac mortality and suggested that this was indicative of left ventricular damage rather than the presence of myocardial ischaemia. $^{2}$

The distribution of patients with significant ST segment depression on exercise was not significantly different between patients on $\beta$ blockers and those who were not. Furthermore, there was no significant difference in the increase in systolic blood pressure on exercise between the two groups. These results suggest that $\beta$ blockers did not have a significant effect on the ischaemic responses obtained on exercise.

The aim of this study was to attempt to identify within the group of patients with ST segment depression those patients with triple vessel disease. Theroux et al reported a one year mortality rate of $25 \%$ in patients with exercise induced ST segment depression; only $2 \%$ of patients without ST segment depression died. ${ }^{1}$ We studied only patients with ST segment depression or a poor haemodynamic response on exercise, and those who had symptoms or were young. Ideally coronary angiography would have been carried out on all patients to determine the distribution of vessel disease in patients with no ST segment depression. We did not consider this approach to be practical or ethical. The prevalence of triple vessel disease in the present study was similar to that previously reported. ${ }^{12}$ Additionally, Akhras et al in a study of 61 patients undergoing exercise testing and coronary angiography after uncomplicated myocardial infarction found that 43 patients with multivessel disease had ST segment depression compared with only two patients with no ST segment depression. ${ }^{13}$ Furthermore, $89 \%$ of patients with triple vessel disease were found within the group with exercise induced ST segment depression. ${ }^{14}$

In an attempt to avoid the problems of differentiating between double and triple vessel disease, comparative studies have identified patients as having either single or multivessel disease (double and triple vessel disease). ${ }^{45}$ Our results have clearly shown that as groups, patients with single, double, and triple vessel disease behave quite differently in terms of their electrocardiographic and haemodynamic responses to exercise. A small proportion of patients with double vessel disease may, however, have exercise responses that resemble those of patients with triple vessel disease. Thus a clear distinction cannot be made between these patients and those with triple vessel disease-an indication of the difficulties of allocating some patients to separate coronary vessel disease groups.

This study has shown that symptom limited exercise testing early after a myocardial infarction is an effective diagnostic technique for identifying patients with severe triple vessel disease. Although we have shown that the presence of ST segment depression alone is a poor indicator of the presence of triple vessel disease, specific analysis of the ST segment changes together with an assessment of the haemodynamic response to exercise can more accurately identify a group of patients who may be at high risk. The simplicity of this approach may be of particular relevance to district hospitals where there 
are adequate facilities for exercise testing but where access to angiographic techniques is restricted and more accurate identification of patients with suspected triple vessel disease is needed.

\section{References}

1 Theroux P, Waters DD, Halphen C, Debaisieux J, Mizgala HF. Prognostic value of exercise testing soon after myocardial infarction. $N$ Engl $\mathcal{f}$ Med 1979;301:341-5.

2 Jennings K, Reid DS, Hawkins T, Julian DJ. Role of exercise testing after myocardial infarction in identifying candidates for coronary surgery. $\mathrm{Br} \mathrm{Med} \mathcal{F}$ 1984;288:185-7.

3 Bruce RA. Exercise testing of patients with coronary heart disease. Ann Clin Res 1971;3:323-32.

4 Sullivan ID, Davies DW, Sowton E. Submaximal exercise testing early after myocardial infarction: difficulty of predicting coronary anatomy and left ventricular performance. Br Heart $\mathcal{f}$ 1985;53:180-5.

5 Schwartz KM, Turner JD, Sheffield LT, et al. Limited exercise testing soon after myocardial infarction; correlation with early coronary and left ventricular angiography. Ann Intern Med 1981;94:727-34.

6 Fuller CM, Raizer AE, Verani MS, et al. Early post myocardial infarction treadmill stress testing; an accurate predictor of multi-vessel coronary disease and subsequent cardiac events. Ann Intern Med 1981;94:734-9.

7 Handler CE. Submaximal predischarge exercise testing after myocardial infarction; prognostic value and limitations. Eur Heart $\mathcal{f}$ 1985;6:510-7.

8 Fioretti P, Brower RW, Maarten L, et al. Prediction of mortality during the first year after acute myocardia infarction from clinical variables and stress test at hospital discharge. Am f Cardiol 1985;55:1313-8.

9 Grande P, Pedersen A. Myocardial infarct size and care diac performance at exercise soon after myocardidy infarction. Br Heart $\mathcal{F}$ 1982;47:44-50.

10 Starling MR, Crawford MH, Richards KL, O'Rourke RA. Predictive value of early postmyocardial infarction modified treadmill exercise testing in muf tivessel coronary artery disease detection. Am Heart f 1981;102:169-75.

11 Thayssen P, Møller M, Haghfelt T, Jagt T. Ventriculas arrhythmias in relation to coronary artery stenosis and left ventricular performance. Eur Heart

12 De Feyter PJ, van Eenige MJ, Dighton DH, Visser FC웅 De Jong J, Roos JP. Prognostic value of exercise testing, coronary angiography and left ventriculograph尹 6-8 weeks after myocardial infarction. Circulatio 1982;66:527-36.

13 Akhras F, Upward J, Scott R, Jackson G. Early exec cise testing and coronary angiography after uncomplicated myocardial infarction. $\mathrm{Br} M e d \mathcal{F} 1982 ; 2840$ 1293-4.

14 Veenbrink Th WG, van der Werf $T$, Westerhof PW Robles de Medina EO, Meijler FL. Is there an indi cation for coronary angiography in patients under $6 \overline{8}$ years of age with no or minimal angina pectoris aftem a first myocardial infarction? Br Heart $\mathcal{F} 1985 ; 5$ 招 $30-5$. 